\title{
On the Anaerobic Metabolism of Three Species of Nereis (Annelida)
}

\author{
U. Schöttler \\ Zoologisches Institut der Universität Münster, Lehrstuhl für Tierphysiologie, Hindenburgplatz 55, D-4400 Münster, Federal \\ Republic of Germany
}

\begin{abstract}
Endproducts of anaerobic metabolism were examined in Nereis diversicolor, $N$. virens and $N$. pelagica. These nereids tend to be exposed to different degrees of hypoxia in their natural habitats. Accordingly, they exhibit different degrees of tolerance to anaerobiosis. The present study reveals: (1) In contrast to all previously examined facultative anaerobe annelids all three nereids produce high amounts of D-lactate. (2) $N$. diversicolor and $N$. virens (to a lesser degree) are able to switch, during longlasting anaerobiosis, to the energetically more convenient degradation of glycogen to succinate and volatile fatty acids. (3) In $N$. pelagica, however, production of volatile fatty acids is only of minor importance. (4) In all three nereids, alanine is accumulated during the beginning of anaerobiosis; but in $N$. virens alanine production continues during longlasting anaerobiosis, although at a lower rate. Variations in responses to anaerobic conditions are also reflected by the 'energy charge', which decreases within $36 \mathrm{~h}$ from 0.88 to 0.66 in $N$. pelagica, whereas in $N$. virens and $N$. diversicolor it decreases within $72 \mathrm{~h}$ from 0.90 or 0.88 , respectively, to 0.70 . The metabolic pathway of energy production during functional anaerobiosis, caused by extensive muscular work (electrical stimulation), was examined. All three species accumulate D-lactate in considerable amounts; however, succinate or volatile fatty acids were not synthesized.
\end{abstract}

\section{INTRODUCTION}

Several members of the genus Nereis live in remarkably different habitats. Nereis diversicolor inhabits the upper region of the tidal zone. Frequently it is found in places covered by water only for one or two hours during high tide. $N$. virens mainly dwells on sublittoral bottoms, but is also found near the low tide level exposed to emergence for 1 or $2 \mathrm{~h}$. N. pelagica lives in the sublittoral phytal. As demonstrated by Theede et al. (1973), these species differ in their ability to survive oxygen deficiency, a fact which may have been expected on the basis of the different habitats occupied. $N$. diversicolor is highly resistant to anoxia, while $N$. pelagica succumbs after a relatively short time; the anaerobic capacity of $N$. virens is intermediate. Theede et al. did not investigate the cause of this striking difference in the tolerance to anoxic conditions. Since differences in metabolic properties appeared to be responsible, I have studied quality and quantity of the metabolic endproducts accumulated during experimental anaerobiosis. Furthermore ATP, ADP and AMP concentrations before and after exposure to anaerobic conditions were measured in order to elucidate the tuderlying energy dynamics.

\section{MATERIAL AND METHODS}

\section{Material}

Nereis diversicolor and $N$. virens were dug out from tidal flats of the German North Sea coast ( $N$. diversicolor at Carolinensiel/Ostfriesland, and $N$. virens at List/Sylt) and kept in artificial sea water $(34 \%$ S) at $6^{\circ}-8^{\circ} \mathrm{C}$ without food for periods of 6 to $14 \mathrm{~d}$ before being used in experiments. N. pelagica were dredged from the phytal of the Kiel Bay (Baltic Sea). They were kept at $8{ }^{\circ} \mathrm{C}$ in artificial sea water $(15 \% \mathrm{~S})$ without food for $4 \mathrm{~d}$. Previous experiments had shown that starvation does not influence the mode of anaerobic metabolism.

\section{Exposure to Anaerobic Conditions}

All experiments were carried out at $12{ }^{\circ} \mathrm{C}$ in artificial sea water (Nereis diversicolor and $N$. virens: $34 \% \mathrm{~S}$, and $N$. pelagica: $15 \%$ S). Five or more test individuals were kept in $800 \mathrm{ml}$ medium in 1-l flasks which could be closed by stopcocks. The test water was flushed with $\mathrm{N}_{2} 1 \mathrm{~h}$ prior and $1 \mathrm{~h}$ after inserting the nereids. Thereafter the stopcocks were closed. 


\section{Electrical Stimulation}

Three individuals of Nereis virens and 5 individuals of $N$. pelagica or $N$. diversicolor were stimulated up to 20 min by 0.5 s pulses of alternating current $(8 \mathrm{~V})$ with a frequency of $12 \mathrm{~min}^{-1}$.

\section{Preparations of Extracts}

At the end of an experiment the worms were rapidly blotted on paper tissue, dropped into liquid nitrogen and ground to powder in a porcelain mortar cooled by liquid nitrogen. The powder, still frozen, was then added to three volumes of ice cold $3 \mathrm{~N}$ perchloric acid, stirred and homogenized in an 'Ultra Turrax' homogenizer. After centrifugation the pellet was extracted once more. Both extracts were combined, neutralized and centrifuged for $30 \mathrm{~min}$ at $45000 \cdot \mathrm{g}$. The incubation water was frozen for later analysis only when all worms had survived the incubation period.

\section{Quantitative Analysis}

D-lactate, succinate, alanine, glutamate, aspartate, ATP, ADP and AMP were estimated by standard enzymatic methods (Bergmeyer, 1974). Volatile fatty acids were measured after steam distillation by gas-liquid chromatography according to Kluytmans et al. (1975).

\section{RESULTS}

Nereis diversicolor and $N$. virens survived anaerobic periods of $72 \mathrm{~h}$ without casualties. In experiments with
$N$. pelagica $40 \%$ of the test animals were found dead after 36 h of anaerobiosis.

There is uniformity in D-lactate being quantitatively the most important endproduct in all three species, but the rates at which it is formed strongly depend on the duration of anaerobiosis. Furthermore, in all three species succinate, acetate and propionate were produced, although in different quantities and varying proportions (Fig. 1).

Rather large quantities of propionate were formed by Nereis diversicolor, much less by $N$. virens and only very little by $N$. pelagica. Most of the propionate was excreted into the medium. After $24 \mathrm{~h}$ the concentrations in the worms were $10-15 \mu \mathrm{mol} \mathrm{g} \mathrm{g}^{-1}$ dry weight in $N$ diversicolor, $8-12 \mu \mathrm{mol} \mathrm{g}{ }^{-1}$ dry weight in $N$. virens and $5 \mu \mathrm{mol} \mathrm{g}{ }^{-1}$ dry weight in $N$, pelagica. These concentrations remained constant over longer exposure periods. Accumulation of succinate was also highest in $N$. diversicolor, very low in $N$. pelagica, with $N$. virens being intermediate. No succinate appeared in the medium. In the three species acetate was produced in rather small quantities and partly excreted into the medium. The concentrations in the worms were nearly the same as reported for propionate.

In order to find out whether amino acids contribute to anaerobic metabolism in the species studied, the concentrations of aspartate, alanine and glutamate were also estimated. The data obtained are shown in Table 1.

In all three species alanine is an endproduct of shortterm anaerobiosis. In Nereis virens also a rather small increase in alanine concentration took place during prolonged anaerobic exposure. No change in glutamate concentration occurred in $N$, pelagica and $N$. diversicolor, whereas a small increase after $24 \mathrm{~h}$ was apparent in $N$. virens.
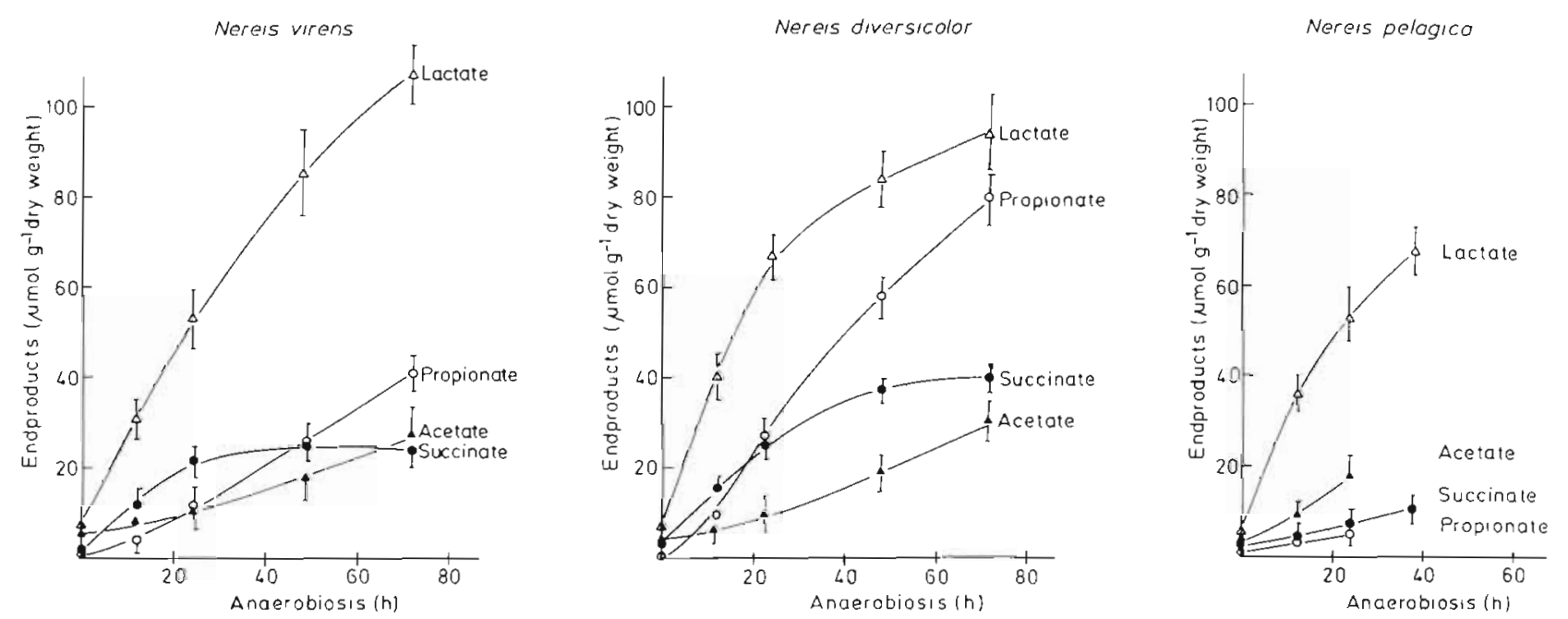

Fig. 1. Concentrations of D-lactate, succinate, propionate and acetate in the nereids specified as a function of duration of exposure to anaerobic conditions. Mean values \pm standard deviation $(N=4)$ 
Table 1. Concentrations of glucogenic amino acids after various periods of anaerobiosis. All values expressed as $\mu \mathrm{mol} \mathrm{g}^{-1} \mathrm{dry}$ weight. Mean values \pm S.D. $(N=4)$

\begin{tabular}{|ccccc|}
\hline Species & $\begin{array}{c}\text { Time of anaerobic } \\
\text { incubation }\end{array}$ & Aspartate & Alanine & Glutamate \\
\hline Nereis diversicolor & 0 & $18.9 \pm 2.5$ & $70.0 \pm 6.7$ & $39.1 \pm 3.2$ \\
& 12 & $3.5 \pm 0.3$ & $83.2 \pm 7.3$ & $43.7 \pm 3.4$ \\
& 24 & $3.9 \pm 0.3$ & $88.4 \pm 5.1$ & $38.3 \pm 3.9$ \\
& 48 & $4.3 \pm 0.9$ & $84.7 \pm 6.8$ & $41.6 \pm 2.7$ \\
Nereis virens & 72 & $6.6 \pm 0.7$ & $92.4 \pm 8.9$ & $40.3 \pm 4.1$ \\
& 0 & $16.8 \pm 0.4$ & $83.1 \pm 8.2$ & $25.5 \pm 1.6$ \\
& 12 & $6.0 \pm 1.1$ & $101.6 \pm 10.1$ & $24.1 \pm 3.5$ \\
& 24 & $2.8 \pm 0.8$ & $116.5 \pm 14.4$ & $26.2 \pm 1.4$ \\
& 48 & $1.5 \pm 0.5$ & $128.6 \pm 16.7$ & $33.2 \pm 3.9$ \\
& 72 & $1.9 \pm 0.4$ & $134.8 \pm 9.8$ & $36.2 \pm 2.8$ \\
& 0 & $7.7 \pm 0.6$ & $35.4 \pm 2.8$ & $23.9 \pm 1.3$ \\
& 12 & $3.2 \pm 0.4$ & $46.3 \pm 3.3$ & $25.5 \pm 0.9$ \\
& 24 & $1.8 \pm 0.6$ & $50.8 \pm 5.3$ & $24.8 \pm 1.4$ \\
\hline
\end{tabular}

In order to assess the relative importance of the different endproducts in relation to anaerobic exposure, the proportions of the sum of the concentrations of all metabolic endproducts were calculated. As is evident from Table 2, the proportions differ greatly in the three species; in addition they depend on the duration of anaerobiosis

In Nereis pelagica D-lactate accounts for more than $50 \%$ of the endproducts accumulated, and alanine for about $28 \%$. Succinate, propionate and acetate, prevailing endproducts in most facultative anaerobes, together make up a share of less than $25 \%$ in this species.

In Nereis diversicolor D-lactate was also the main endproduct during the first $24 \mathrm{~h}$, but during prolonged anaerobiosis its proportion decreased to $25 \%$. During the first $24 \mathrm{~h}$ the amount of alanine was $15 \%$ of the total. Succinate, propionate and acetate increased from
$37.5 \%$ after $12 \mathrm{~h}$ to more than $70 \%$ between 48 and $72 \mathrm{~h}$ of anaerobiosis.

Concerning the accumulation of D-lactate, Nereis virens is intermediate between $N$. diversicolor and $N$. pelagica. The share of $\mathrm{D}$-lactate was found to be close to $40 \%$ during different periods of exposure. At prolonged anaerobiosis, between 48 and $72 \mathrm{~h}$, the percentage of volatile fatty acids accumulated increased to nearly $40 \%$. Although the concentration of alanine increased rather slowly during anaerobic exposure its percentage of the total accumulation of the metabolites decreased.

Table 3 shows the concentrations of adenosine phosphates estimated in the worms after different periods of anaerobiosis. It is evident that in all Nereidae studied ATP decreased from its initial level as anaerobic exposure was extended. However, there are striking differences between the species. In Nereis pelagica ATP

Table 2. Percentages of the endproducts listed

\begin{tabular}{|c|c|c|c|c|c|c|c|}
\hline Species & Time $(\mathrm{h})$ & D-Lactate & Succinate & Propionate & Acetate & Alanine & Glutamate \\
\hline \multirow[t]{4}{*}{ Nereis diversicolor } & $0-12$ & 46.1 & 15.4 & 11.9 & 8.4 & 18.2 & - \\
\hline & $12-24$ & 42.2 & 15.6 & 29.7 & 4.7 & 7.8 & - \\
\hline & $24-48$ & 25.3 & 19.4 & 43.2 & 11.9 & - & - \\
\hline & $48-72$ & 20.4 & - & 49.0 & 30.6 & - & - \\
\hline \multirow[t]{4}{*}{ Nereis virens } & $0-12$ & 44.1 & 11.9 & 8.5 & 5.1 & 30.5 & - \\
\hline & $12-24$ & 37.3 & 18.6 & 11.9 & 6.8 & 25.4 & \\
\hline & $24-48$ & 40.5 & 7.6 & 20.2 & 8.8 & 15.7 & 7.6 \\
\hline & $48-72$ & 42.6 & - & 24.1 & 16.7 & 11.1 & 5.6 \\
\hline \multirow[t]{2}{*}{ Nereis pelagica } & $0-12$ & 60.0 & 4.4 & 4.4 & 6.7 & 24.4 & - \\
\hline & $12-24$ & 53.1 & 9.3 & 6.3 & 18.8 & 12.5 & \\
\hline
\end{tabular}


Table 3 . Concentrations of adenosine phosphates ( $\mu \mathrm{mol} \mathrm{g} \mathrm{g}^{-1}$ dry weight) and the calculated 'energy charge after various periods of anaerobiosis

\begin{tabular}{|c|c|c|c|c|c|c|}
\hline Species & Time (h) & ATP & ADP & AMP & $\mathrm{ATP}+\mathrm{ADP}+\mathrm{AMP}$ & Energy charge \\
\hline \multirow[t]{5}{*}{ Nereis diversicolor } & 0 & 9.73 & 2.28 & 0.29 & 12.30 & 0.88 \\
\hline & 12 & 8.68 & 3.08 & 0.74 & 12.50 & 0.82 \\
\hline & 24 & 7.43 & 3.22 & 0.99 & 11.64 & 0.78 \\
\hline & 48 & 6.08 & 3.68 & 1.28 & 11.04 & 0.72 \\
\hline & 72 & 5.71 & 3.84 & 1.32 & 10.87 & 0.70 \\
\hline \multirow[t]{5}{*}{ Nereis virens } & 0 & 10.16 & 1.82 & 0.27 & 12.25 & 0.90 \\
\hline & 12 & 8.68 & 2.48 & 0.57 & 11.73 & 0.85 \\
\hline & 24 & 8.04 & 3.39 & 0.84 & 12.27 & 0.79 \\
\hline & 48 & 6.88 & 3.68 & 1.26 & 11.82 & 0.74 \\
\hline & 72 & 5.82 & 3.73 & 1.37 & 10.92 & 0.70 \\
\hline \multirow[t]{4}{*}{ Nereis pelagica } & 0 & 11.26 & 2.79 & 0.34 & 14.39 & 0.88 \\
\hline & 12 & 9.68 & 3.42 & 0.88 & 13.98 & 0.81 \\
\hline & 24 & 7.44 & 3.87 & 1.25 & 12.56 & 0.75 \\
\hline & 36 & 5.71 & 4.28 & 1.97 & 11.96 & 0.66 \\
\hline
\end{tabular}

dropped to nearly $50 \%$ of the normal value within $36 \mathrm{~h}$, whereas in $N$. virens and $N$. diversicolor the decrease of ATP was much slower: after $72 \mathrm{~h}$ the ATP content was nearly $60 \%$ of the initial level in both species. The concentrations of ADP and AMP obviously increased in all worms during anaerobiosis, but in $N$. diversicolor and $N$. virens maximum concentrations were reached within $48 \mathrm{~h}$; simultaneously a decrease of the tota]. content of adenosine nucleotides was observed. The quotient (ATP) + $1 / 2$ (ADP)/(ATP) + (ADP) + (AMP) was calculated from the concentrations of adenosine nucleotides. Termed 'energy charge' of the adenosine system, this quotient was introduced in 1967 by Atkinson and Walton. It can vary between 0 and 1.0 and is an excellent parameter for calculating the energy content of a system. The basal metabolism of an animal cell is characterized by an energy charge between 0.88 and 0.92 . A decrease of the energy charge is assumed to indicate excessive stress. In $N$. pelagica the energy charge dropped from 0.88 to 0.66 during $36 \mathrm{~h}$ of anaerobiosis. In $N$. virens and $N$. diversicolor there was a much slower decrease; a value of 0.70 was attained after $72 \mathrm{~h}$ of anaerobiosis.

In addition to the measurements described, the water content of the worms was determined during anaerobiosis. All three species were shown to take up water, although in different proportions. In Nereis virens and $N$. diversicolor the water content only increased from 79 to $82 \%$ of the fresh weight within $72 \mathrm{~h}_{i}$ in N. pelagica the water uptake was substantially higher, increasing from 80 to $87 \%$ of the fresh weight within $36 \mathrm{~h}$.

As lactate is preferentially formed during extensive muscular activity, and Nereidae are very motile annelids, all three species were subjected to electrical stimulation in order to evoke maximum muscle work.

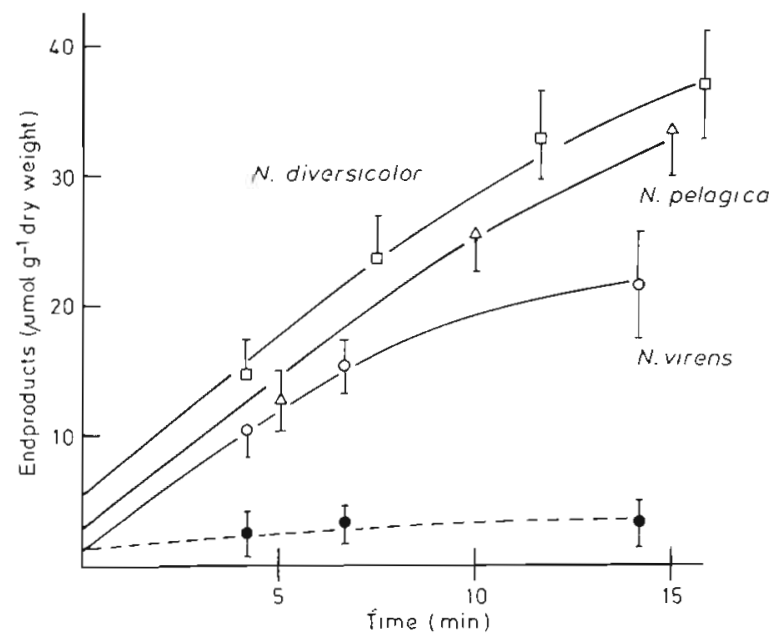

Fig. 2. Formation of D-lactate and succinate in the nereids specified following electrical stimulation. Solid lines: D-lactate; dotted line: succinate. The succinate concentration shown, is representative of all three species

In Figure 2 the results of these experiments are shown. After electrical stimulation D-lactate was accumulated in considerable concentrations, but no succinate was produced under these conditions by all three species.

During their individual development many Nereidae are most active at the beginning of sexual maturation, when they switch from living at the bottom and in caves to continuous swimming close to the water surface until reproduction and following death. Heteronereid individuals of Nereis virens were examined for accumulation of typical endproducts of anaerobic metabolism after strong and continuous swimming for $30 \mathrm{~min}$. Contrary to sexually immature individuals, however, neither succinate nor lactate could be detected at this stage. 


\section{DISCUSSION}

In all animals glycogen is the main fuel for anaerobic energy production. In invertebrates two metabolic pathways for anaerobic glycogen breakdown are known: (1) The Embden-Meyerhof pathway leading to the accumulation of lactate or, in some cases in a modified form, to the formation of octopine or ethanol. (2) A pathway in which phosphoenolpyruvate is carboxylated to oxaloacetate giving rise to malate and succinate and finally to volatile fatty acids as propionate and acetate

In the Nereidae studied both alternatives of anaerobic energy production occur together. As these analyses show, the ratio of lactate to volatile fatty acids formed differs anaerobically from species to species. It is conspicuous that the capacity to form volatile fatty acids parallels the ability to survive periods of anaerobiosis. Nereis pelagica, with its relatively low tolerance to anaerobic conditions, produces succinate and volatile fatty acids only to a minor extent and acetate production exceeds the synthesis of propionate. $N$. diversicolor, however, which produces predominantly lactate during an early phase of anaerobiosis, apparently switches to volatile fatty acid formation during prolonged anoxia. It is still unknown how this change is effected. Although the production of D-lactate decreases drastically, its formation still continue to some degree during prolonged anaerobiosis. Possibly, the continuous formation of lactate at a decreased rate is due to some tissues which are unable to switch to the production of volatile fatty acids or at least have difficulties in doing so.

Nereis virens occupies an intermediate position between $N$. pelagica and $N$. diversicolor. Volatile fatty acids increased absolutely and relatively during prolonged anaerobiosis. However, the absolute increase is distinctly lower than in $N$. diversicolor and the increase of the percentage of the metabolites is due to the fact that during prolonged anoxia alanine only rises very slowly and succinate does not increase at all. Lactate accumulation in relation to the formation of the other metabolic endproducts remains constant over $72 \mathrm{~h}$ of anaerobiosis in $N$. virens, contrary to $N$. diversicolor.

Nereidae also accumulate alanine in addition to lactate, succinate and volatile fatty acids. As in other facultative anaerobes (Schöttler and Schroff, 1976; de Zwaan, 1977; Felbeck, 1979) alanine accumulation in Nereis diversicolor only takes place shortly after the onset of anaerobiosis. On the other hand, $N$. virens apparently accumulates alanine as long as the anaerobic state lasts. The significance of alanine production for anaerobic energy production is still unknown. In other annelids the C-skeleton of this amino acid was shown to be derived from glycogen (Zebe, 1975; Schöttler and Schroff, 1976); however the origin of the amino group remains unexplained. Theoretically it seems possible that aspartate, which is metabolized during the initial phase of anaerobiosis, may be the main donor of this group. However, most of the aspartate is metabolized during the first hour of anaerobiosis and at this time the increase of alanine concentration does not parallel the decrease of aspartate; it was found to be distinctly lower.

While in Nereis pelagica and in $N$. diversicolor the concentrations of glutamate remained constant during anaerobiosis some increase was found in $N$. virens during prolonged anoxia, as has been reported previously from Tubifex tubifex (Schöttler and Schroff, 1976). The origin of this accumulated glutamate is still unknown.

The results presented here indicate that the degree of resistance to anaerobic conditions is coupled with the capacity to produce volatile fatty acids from carbohydrates. The death of Nereis pelagica after rather short periods of anoxia is probably caused by insufficient rates of ATP formation. This seems obvious from rapid decrease of the energy charge. However, in Arenicola marina body-wall musculature, similar values (0.65) were measured after $24 \mathrm{~h}$ of anaerobiosis without lethal effects to this species (Surholt, 1977). Therefore, still other causes - in addition to falling energy charge - must be responsible for the low anaerobic resistance of $N$. pelagica. Since $N$. pelagica takes up substantially more water during anaerobiosis than the other species studied, osmotic imbalance might be an additional cause of the low anaerobic resistance of this species. This presumption is supported by the observation of Theede et al. (1973) that $N$. pelagica is rather sensitive to changing osmotic conditions.

The question still remains, why the capability of lactate formation is so highly developed in Nereidae. Unlike other facultative anaerobic annelids, Nereidae are quite mobile. They are able to swim and creep quickly by twisting their body and using their parapods as levers. This twisting is mainly performed by the longitudinal musculature, in which mitochondria are quite rare (Lindner and Fischer, 1964; Defretin and Wissocq, 1969). Probably, the capacity for aerobic energy production of the muscles cannot meet the energy demand during exercise. Therefore these muscles have to rely on lactate formation or, in other words, the muscles of Nereidae may have been developed to meet functional anaerobiosis to varying degrees in addition to environmental anoxia.

In mature heteronereid individuals, however, the situation is completely different. Their parapods have greatly increased in size, and function as oar blades, 
enabling the worms to swim quickly and for a long time almost without interruption. The impossibility to demonstrate the accumulation of anaerobic endproducts in heteronereid forms of Nereis virens agrees well with the results of electron microscopic investigations, showing the muscle cell of heteronereis of $N$. irrorata and of Perinereis cultrifera being well equipped with mitochondria (Lindner and Fischer, 1964; Defretin and Wissocq, 1969). Thus the worms are adapted excellently to long-lasting muscular activity, which is probably the basis of successful reproduction in the free water close to the surface.

Acknowledgements. I wish to thank Dr. Kesseler, Biologische Anstalt Helgoland, Litoralstation List/Sylt, and Prof. Dr. Theede, Institut für Meereskunde an der Universität Kiel, for their hospitality and their help in obtaining Nereis virens and $N$. pelagica. This paper was supported by a grant from the Deutsche Forschungsgemeinschaft (Gr, 456/6)

\section{LITERATURE CITED}

Atkinson, D. E. and Walton, G. M. (1967). Adenosine triphosphate conservation in metabolic regulation. J. biol. Chem., 242, 3239-3241.

Bergmeyer, H. U. (1974). Methoden der enzymatischen Analyse, 4th. ed. Verlag Chemie, Weinheim.
Defretin, R. and Wissocq, J. C. (1969). La musculature longitudinale dorsale et ventrale des Nereis irrorata Malm. gren (Annelides Polychetes) atoques et epitoques. C. $I$ hebd. Séanc. Acad. Sci. Paris, 249, 2117-2120.

Felbeck, H. (1979). Die Rolle der Aminosäuren im Stoffwechsel von Arenicola marina: Bedeutung für Osmoregulation und Anaerobiose. Ph. D. thesis, University of Münster, FRG

Kluytmans, J. H. F. M., Veenhof, P. R. and de Zwaan, A. (1975). Anaerobic production of volatile fatty acids in the sea mussel Mytilus edulis L. J. comp. Physiol., 104, 71-78.

Lindner, E. and Fischer, A. (1964). Zur Feinstruktur nereider und heteronereider Muskulatur von Platynereis dumerilii. Naturwissenschaften, 17, 410.

Schöttler, U. (1978). Investigations of the anaerobic metabolism of the polychaete worm Nereis diversicolor $M$. J. comp. Physiol., 125, 185-189.

Schöttler, U. and Schroff, G. (1976). Untersuchungen zum anaeroben Glykogenabbau bei Tubifex tubifex $M$. J. comp. Physiol., 108, 243-254.

Surholt, B. (1977). The influence of oxygen deficiency and electrical stimulation on the concentration of ATP, ADP, AMP and phosphotaurocyamine in the body-wall musculature of Arenicola marina. Hoppe-Seyler's Z. physiol. Chem., 358, 1455-1461.

Theede, H., Schaudinn, J. and Safe, F. (1973). Ecophysiological studies on four Nereis species of the Kiel bay. Oikos, 15 (Suppl.), 246-252.

Zebe, E. (1975). In vivo-Untersuchungen über den GlucoseAbbau bei Arenicola marina (Annelida, Polychaeta). J. comp. Physiol, 101, 135-145.

Zwaan, A. de (1977). Anaerobic energy metabolism in bivalve molluscs. Oceanogr. mar. Biol. A. Rev., 15, 103-187.

This paper was presented by Dr. D. Siebers; it was accepted for printing on October 3, 1979 